\title{
Influence of Television on the Sexual Behavior of Young Women in Mlolongo Township of Machakos County, Kenya
}

\author{
Rhoydah Nyambane ${ }^{1^{*}}$, Ndeti Ndati ${ }^{2}$ \\ ${ }^{1 *}$ Department of Communication and Media Studies, The Technical University of Kenya, PO Box 52428, 00200, \\ Nairobi \\ ${ }^{2}$ School of Journalism and Mass communication, University of Nairobi PO Box 30197, 00100 Nairobi
}

\begin{abstract}
The research set out to analyze the influence of television messages on sexual behavior of young women aged between 15 and 24 in Mlolongo Township in Machakos County, Kenya. The objective was to investigate the relevance of the television messages in addressing the issues that make young women more vulnerable to HIV/AIDS than young men of the same age. The study site was chosen because the town is situated along the busy Nairobi-Mombasa highway, where the weighbridge is situated, making the town a sexual hub for truck drivers who spend days in the town as they wait for their tracks to be weighed; thus making it a rich spot for the spread of HIV/AIDS. The study employed the exploratory research design to collect data from the sample population. Data collection was through the use of the questionnaire method administered on a face-to-face basis to the respondents. The sample size was 60 respondents who were selected using a random sampling method. The findings indicated that awareness on the mode of transmission, prevention and management of the HIV/AIDS was almost 100 percent. Majority of the respondents had had access to TV messages that contained messages on HIV/AIDS. However, the TV viewing a lone was not sufficient enough to help change the women's sexual behavior. Other underlying factors such as cultural beliefs, gender, poverty, peer pressure, economic dependence on male partners made the women more vulnerable to HIVIAIDS and not necessarily lack of knowledge on HIV/AIDS. There was therefore need for change of strategy on the fight against HIV/AIDS and not merely awareness creation and prevention. There was need for stakeholders and to have a concerted effort towards addressing the issues at which young women are vulnerable to HIVIAIDS and not necessarily creating awareness, which, according to the study, was almost 100 percent.
\end{abstract}

\section{Introduction}

Over twenty-five years have passed since the first diagnosis of HIV, the virus that causes in the world. While there were a handful of women among the first AIDS cases, they (women) have emerged as another group that is hard hit by the HIV and AIDs epidemic (KAIS, 2007, KDHS, 2003). HIV/AIDS has claimed more than 20 million lives worldwide and some 37 million people are living with the virus. Each year, one million people die of the virus. According to figures from UNAIDS (2003), Sub- Saharan Africa accounts for about 70 percent of the world's HIV/AIDS infection, 25 million of the 37.8 million people living with the HIV/AIDS worldwide. In Kenya 2 million people are infected (NACC, 2000). Since HIV/AIDS was discovered in 1981, it has become one of the most devastating infectious diseases globally. It is the forth most common causes of premature death in the world, and the leading cause of death in Africa. Of approximately 60 million people who had been infected with HIV since the beginning of the epidemic, more than 20 million had died of AIDS by the end of 2003 (UNAIDS/WHO, 2003). In 2004, there were about 3.1 million AIDS deaths worldwide. In the same year, about 4.9 million new infections occurred, approximately 14,000 people per dayresulting in more than 39.4 million people living with HIV/AIDS worldwide. In that year, $60 \%$ of some 25.4 million on the infected people were living in Sub-Saharan Africa where the pandemic is causing particular devastation. The average HIV prevalence among adult population across Sub-Saharan Africa is $7.4 \%$ (UNAIDS/WHO, 2004).

\section{Vulnerability of Women to HIV and AIDS}

Young women are particularly a vulnerable population in Kenya, a country where majority of the population becomes sexually active between ages 15 and 24 . This is due mainly to vulnerability. Majority of them are sexually active and desire to experiment due to peer pressure. Coupled with living in high-risk areas like Mlolongo, poverty, gender-based violence including rape, economic dependence and cultural practices and beliefs makes their vulnerability grave. Among young women, HIV infections are sexually transmitted or associated with pregnancy, childbirth and breast-feeding health initiatives, women with violent or controlling male partners are at increased risk of HIV infection, partner violence, male-dominance in relationships, physical violence, sexual coercion and cultural beliefs where the society tolerates male promiscuity and the woman is 
supposed to abide by that, hence endangering her life. There should be an acknowledgement that there is linkages between HIV/AIDS and sexual and reproductive health, and explain their relationship within the broader issues of public health, development and human rights.

Current measures of HIV prevalence and care have affected HIV/AIDS incidence, prevalence and clinical presentation positively. However, despite recent trends of falling prevalence among people especially in adolescent girls in Uganda and South Africa, overall, about three times as many young women as men are infected in Sub-Saharan Africa. In 2004, an estimated 3.1 million (2.7-3.8) million people in the region became newly infected, while 2.3 died of AIDS (KNHIV/AIDS SP: 2005 to 2010). Among young people aged between 15 and 24 years, an estimated 6-9 of women and 2.2\% (2.0-2.7\%) of men were living with HIV at the end of 2004. African girls and women are particularly vulnerable to HIV infection. Women are about half of all people living with HIV/AIDS world wide, but sub-Saharan Africa women are 58 percent of the people living with HIV/AIDS. Young women aged 15 to 24 were 2.5 percent are more likely to be infected than young men. HIV/AIDS has become a tragedy of devastating proportions globally. HIV/AIDS affects the productive and profitability of businesses with economic implications well into the future. AIDS creates a unique demand at all levels of society (AIDSCAP/FHI, 1996). Africa bears much of the burden of these devastating statistics, with 25 million people living with HIV/AIDS. Various strategies towards the eradication/management of the virus have put several intervention strategies in place. Among them are abstinence, condom use, faithfulness to one partner of known HIV status and addressing stigma spearheaded largely by the government, non-governmental organizations, health professionals and the media. But these strategies are not bearing much fruit because new infections are being reported on a daily basis.

It is estimated that 7000 young people aged between 10 and 24 are infected with the virus daily; that is about 5 young people every minute. About 1.7 million young people in Africa are infected with HIV every year, with 700, 000 being Asia and the Pacific. (UNAIDS, 2001). In Kenya, 80-90 percent of infections are among people aged between $15-24$ years, (AIDSCAP/FHI 1996). HIV/AIDS infections are concentrated in the least developed countries (LCD) with $89 \%$ of people with HIV/AIDS living in Sub-Saharan Africa and Asia. Over $2 / 3$ of all the people living with the virus, 22 million live in Africa. It is estimated that $87 \%$ of children living with HIV/AIDS in the world live in Africa (NACC, 2000). More than any other disease, HIV/AIDS is a social and medical problem. The primary mode of transmission is through heterosexual contact and the epidemic varies greatly across demographic groups. HIV prevalence is nearly two/three times higher among adult women compared to men; and varies by region and across socio-economic class and it is higher among the poorest compared to the rich in the both rural and urban areas (The Body .org). In Kenya, the first case of HIV was diagnosed in 1984. The Kenya Demographic and Health Survey (KDHS: 2003) estimated that 1.2 to 1.5 million people in Kenya between ages of 15 to 49 were infected by HIV (KNGN \& NIV/AIDS, MOH, 2007).

The action framework for the fight against the HIV/AIDS epidemic in Kenya focuses on three major priority areas: prevention of new infections, improvement of the quality of life of people infected and affected by HIV/AIDS and mitigation of the socio-economic impact of HIV and AIDS (KAIS, 2007). Women risk becoming infected at a much younger age than boys do. They are vulnerable to HIV biologically, socially and economically. Gender inequality fuels HIV crisis among women (Overall and Zion 1999). The proportion of HIV and AIDs cases among women has more than tripled from 8\% in 1985 to an alarming 27\% in 2008 (The Body.org). HIV has become the third most deadly disease for women, behind cancer and heart disease in Kenya. The epidemic among young women thrives on poverty, gender-based violence including rape, dependency and vulnerability. Majority of women who are fully aware of the threat of HIV are unwilling or unable to protect themselves and their partners because of poverty and vulnerability. HIV prevalence is nearly two/three times higher among adult women compared to men; and varies by region and socio-economic class; and is higher among the poorest compared to the rich in rural and urban areas, and gets worse in high-risk areas. The high level of new infections among young women and their vulnerability is an area of growing concern. A number of comprehensive, integrated interventions have been employed by various organizations including the government, NGOs, health professionals and the church. One of the major preventive and care strategies is the mass media and in particular, the TV messages which was the focus of the study. Among the strategies used in most TV programs that target HIV/AIDS prevention include total abstinence, condom use, VCT - knowing one's status, faithful to one partner of known status (wacheni mpango wa kando, translated as stop having other relationships besides your partner), a popular TV advert. Other TV soaps like Siri (translated as 'secret', Makutano Junction, Churchhill Life, Nakufeel, Mother in Law, male circumcision and so on to convey messages on HIV/AIDS.

The study critically analyzed the influence of TV messages on HIV/AIDS among young women aged between $15-24$ in Mlolongo Township, a high risk town due to strategic position a long the Mombasa highway and the kind of lifestyle necessitated by the long distance truck drivers who spend considerable amount of time in the town as they wait for their trucks to be weighed at at the weigh bridge located there.. Majority of the 
young women found in the town are dolescents who are sexually active due to peer pressure, desire to experiment, sexual exploration, vulnerability, poverty among others.

\section{Problem sstatement and study scope}

Since its discovery, HIV/AIDS has continued to cause havoc especially women due to various socioeconomic, culture, gender factors, sexual activity, poverty, sexual harassment including rape, economic dependence and so on. Women cannot demand that their partners use condoms or engage in safe sex yet they depend on them for economic support. Women therefore tend to be at risk not because of their own behaviors but because of the behaviors of their partners. The general observation is that there is a gap between information dissemination and behavior change WHO (2004), Kenya AIDs Indicator Survey(2007) and the Kenya Demographic Health Survey (2009). The objectives of the study was to investigate the relevance of TV messages in addressing the issues that make women more vulnerable to HIV/AIDS than men. The research was to critically analyze the influence of TV messages on sexual behavior of young women between 15 and 24 years in Mlolongo Township. Mlolongo was chosen as the study site because of its strategic position along the Nairobi- Mombasa- Malaba highway and the presence of the weighbridge and leads to large numbers of truck drivers lodging in the town.

\section{Literature review}

Literature reviewed was related to this study's main objectives on whether media messaging especially in the TV influenced sexual behavior change among young women aged between 15 and 24 in the study site. Emphasis was put on other prevention strategies viz a-viz TV influence on women's vulnerability to HIV/AIDS and whether messages have attempted to address the underlying factors that make young women more vulnerable to HIV/AIDS besides creating awareness. While acknowledging the importance of T.V. on HIV/AIDS prevention, NASCOP (2005) points out that these interventions have failed to yield positive results. There is therefore need to go beyond raising awareness on HIV/AIDS and address other factors that make women more vulnerable compared to men. Although concerns have often been raised about television's role as a "teacher" about sexuality, little is known about the specific content of sexual messages on the programs adolescents and children watch. So most of the messages may not be tailored to meet the specific needs of each specific audience and hence they may not meet their overall goal (http//www.springerlink.com 12/10/2010).

\section{Role of Television in combating HIV /AIDS}

The media have a very important role to play in combating the HIV/AIDS scourge. In the recent past, particularly between 2003 and 2009, there have been some bold and media messages in the mass media particularly print and electronic that have targeted different certain behaviors among young women especially adolescents. Many organizations including government, NGOs and other development partners have come up with developed strategies to promote awareness of HIV/AIDS and prevent its spread. Research has shown that IEC messages in the media are especially very effective on awareness creation but have limited impact on behavior change. The media that have been used include the radio, television, billboards, bumper stickers and newspapers.

Kenyan audiences are fragmented along the various media channels. Over 39\% of Kenyans watch TV, over $90 \%$ listen to radio, 23\% read newspapers. Nearly 3 million use Internet services while over 14 million use mobile phones. Over 3.2 million households have TV sets across the country. There are more TV viewers in urban centers than in rural areas. Urban areas enjoy higher standards of living than in rural areas and have better access to TV resources (Oriare,Ugangu and Okello, 2010). From the variety of the campaigns and the abundance of messages aired through various media, there is no doubt that the messages are sent, transmitted and probably received by the target audience. The main objectives of the messages concentrated on awareness creation but did not emphasize behavioral change issues that affect the vulnerable groups. This study identified that without effective behavior change communication strategies, efforts aimed at averting the spread of HIV/AIDS will not be successful and new infections will continue to be reported. Therefore the study sought to identify those gaps and make recommendations that can help shape behavior change strategies in the fight against HIV/ AIDS.

Based on this and other emerging trends, this study aimed at examining the T.V messages in combating HIV/AIDS in Mlolongo Township with a view to critically looking at how these messages are presented, the prominence given to them on the T.V timing, how they have been packaged, the target audience and their presentation. The study examined the aim of the messages and what they are meant to achieve and whether they have achieved their major aim; that is to change behavior on HIV/AIDS prevention. Family Health International Activity report (2008), recognizes that an effective response to the spread of HIV is very important but cannot be limited to awareness campaigns and expanded care, support and treatment. Underlying social factors such as alcohol abuse, gender-based violence and joblessness are significant barriers to service uptake and the adoption 
of safer sexual practices. Since 1999, communication-related interventions have been key components of FHI's Implementing AIDS Prevention and Care. Behavior change communication (BBC) was an essential part of these interventions, which aim to help people increase their knowledge of HIV and AIDS, change their attitudes and beliefs, modify their reception of risks, and build skills in adopting and maintaining healthy behaviors (FHI, 1999-2006). However, this has not been done because all the efforts are aimed at awareness creation and prevention strategies aimed at the general population and not particularly targeted at women and hence of this study

\section{Theoretical framework}

The Social Learning Theory was formulated by Albert Bandura ( 1997). It encompasses concepts of traditional learning theory and the operant conditioning of B.F Skinner. The theory has been useful in explaining how people can learn new things and develop behaviors by observing other people. It is assumed therefore that Social Learning Theory is based on observational learning process among people. The mass media more so the T.V. have become important socialization agents as well, creating and shaping many of our shared attitudes, values, behaviors and perceptions of social reality. The influence of the mass media in the acquisition of response tendencies is often referred to as 'social effects'. Bandura's Social Learning Theory is relevant to this study due to its suitability to help change behavior. As the theory proposes, people learn by observing behavior on TV or any other medium. The main objective of this study was to examine whether messaging through T.V. was the most effective way to change behavior of women who are vulnerable to the HIV/AIDS pandemic in the study site. As the theory proposes, there is reward for adhering to TV messages on HIV/AIDS because if they abstain from risk behavior, then they will live longer, healthier and fruitful lives as opposed to dying early besides having to deal with the opportunistic infections and spending large sums of money on drugs. The theory also says that it is fortunate that people can learn from observation since mistakes can be very costly. Therefore, if one does not adapt to T.V. messages on HIV/AIDS prevention by ignoring the messages, then the mistakes can be very costly i.e. living with the consequences of contracting HIV.

\section{Research Design and Methodology}

This study employed explanatory research because this type of design is used to answer the question 'why' and 'how' things happen the way they do. It establishes a cause and effect relationship between two variables through the use of questionnaires, interviews, random sampling to gather the information. The study employed simple random sampling because it enabled the sample to be as representative of the population as possible to allow for an accurate generalization of the results. The method used was first to identify the target population (women aged 15 to 24 ) in various social joints within the town e.g. churches and colleges that run vocational training centers, VCT centers, and hair salons. Then carried a random to identify the respondents to whom the questionnaires were administered.

\section{Data collection and analysis}

The study employed quantitative data collection method using a structured questionnaire that was administered to the respondents. Questionnaires were given to the respondents on a face-to-face basis to fill while other respondent preferred to fill them through a drop -off procedure. The study chose quantitative method because it covered the diverse objective needs of the researcher andit sought objective as opposed to subjective approach. The data collected was analyzed in tables and graphs so as to facilitate understanding in line with research topic and objective. The study used the Statistical Program for Social Sciences (SPSS) to organize the data collected from questionnaires. Majority of the respondents were aged between 20-24 years at $66.7 \%$ while the rest were between 15 and 19 years of age at 33.3\%, the target population of this study. Majority of the respondents were young and unmarried women at $71.7 \%$, implying that they could be more at risk of HIV infection because of vulnerability due to socio-economic conditions under which they live. $76.7 \%$ were unemployed meaning that they did not have a source of livelihood and the issue of how they sustained their livelihood came up. One of the assumptions of the study was that poverty was among the reasons why young girls in Mlolongo are vulnerable to HIV/AIDS and because there is easy money from truck drivers, whom they can depend on for their upkeep, hence exposing them to the risk of HIV infection. 


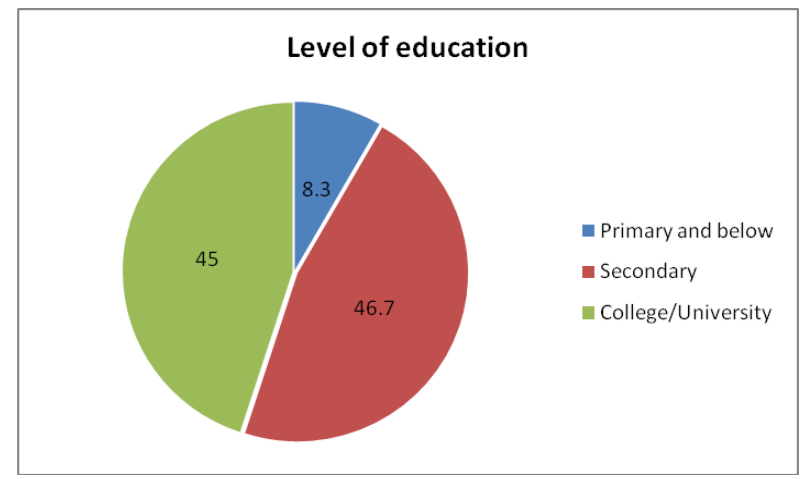

Figure 4: Level of education attained (\%)

In this study, nearly half of the respondents have completed their secondary level education and college level. Very few were below primary level $(8.3 \%)$. Education attainment relates to a person's ability to access information from media and its various outlets. Education level also relates to the individual's knowledge to choose certain media and also use them to access news. It also indicates that one has the ability to choose what to watch and apply the information in their daily lives.

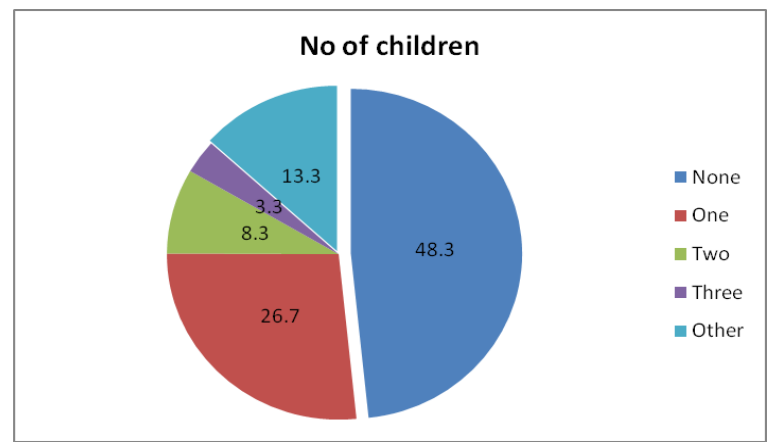

Figure 5: Number of children (\%)

Nearly half of the respondents $48.3 \%$ had no children. Another 26.7 had one child; $83 . \%$ of the respondnets have two children while a small number of respondents $3.3 \%$ have three children and $13.3 \%$ did not specify the number of children they had. This means that all the respondents were sexually active in one way or the other either in a marriage realtionship or otherwise and therefore vulnerable to HIV and AIDS. According to the findings, majority, $78 \%$, lived with relatives or family members while $21.7 \%$ did not live with family members. Coupled with $76.7 \%$ who indicated that they were not in any gainful employment, the questions therefore that begged for answers were: what was the source of livelihood for these girls who did not live with relatives or friends and yet have no source of income? How did they meet their daily needs? Chances are that they are engaged in risky behavior to earn a living and therefore formed a good sample for future research

\section{Relevance of TV Messages on Vulnerability to HIV/AIDS}

All the respondents (60 or 100\%) had access to TV and indicated that they watched one TV program or another. That means that they got their information on HIV/AIDS through watching various TV programs as illustrated by the research findings. This means that TV is an effective medium to communicate messages on HIV/AIDS. Majority of the respondents watched one program or the other. The programs that were watched mostly by the respondents were drama and soaps. Soaps were the highest at $21.7 \%$ while drama followed with $20 \%$. Advertisements were watched by $10 \%$ of the respondents while $8.3 \%$ watched all programs. The rest watched a mixture of the programs. Drama and news stood at 5\%; drama, news, soaps, advertisements at $3.3 \%$; drama, news advertisements $1.7 \%$; drama, soaps $1.7 \%$; drama soaps, advertisements $1.7 \%$; news, soaps $6.7 \%$; news advertisements $6.7 \%$; soaps and advertisements a3.3\%.

All the respondents agreed that many of the programs they watched had a message on HIV/AIDS but in varied proportions. This means that awareness on HIV and AIDS through TV messaging was 100\%. However, it shows that TV viewership and behavior change were not in direct correlation; implying that TV viewership did not necessarily translate into behavior change. As pointed out by Wyss (2001), mass media messages are an important source of knowledge regarding HIV and AIDS but this knowledge a lone does not translate to behavior change. Other issues underlying HIV and AIDS infection among vulnerable groups are not taken into account and new infections continue being reported (UNAIDS 2007). 


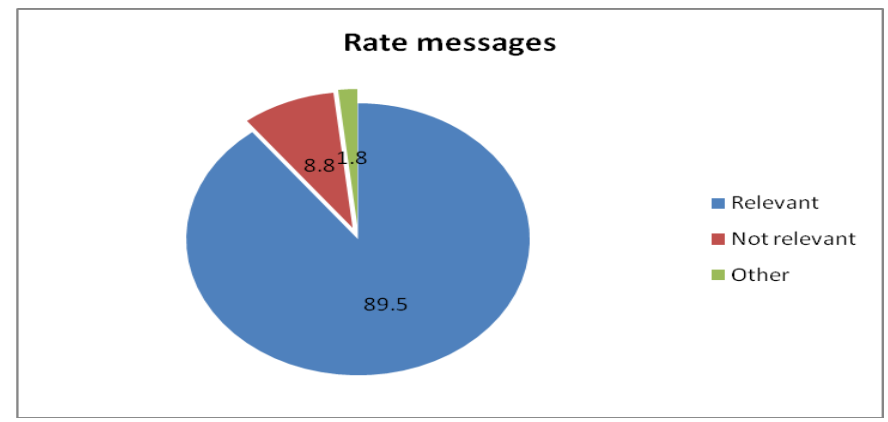

Figure 10: Relevance of messages (\%)

Again majority of the respondents agreed that the messages on HIV/AIDS in the programs they watched were not relevant at $89.5 \%$. Only $8.8 \%$ felt that the messages were relevant and only $1.8 \%$ could not tell whether they were relevant or not. According to the findings in this study, $74.6 \%$ did not changed behavior as a result of watching programs on TV while $25.4 \%$ change behavior as a result of watching TV. This means that HIV/ AIDS prevention through messaging on TV is not the most efective way of changing behavior as some of the girls are still vulnerable to HIV/AIDS despite watching TV messages on the same. Even those who had changed behavior may not have done so $100 \%$. Meaning that there is still more that needs to be done to achieve desired positive behavior change among young girls in Mlolongo. Women are faced with the dilema of choosing to die of hunger or HIVAIDS. Others said that dying of AIDS is no different from dying from other illnesses including hunger so why suffer from poverty when men can provide their source of livelihood and at the end of the day everybody will die of one cause or the other? These are the tricky situations that need to be addressed by relevant stakeholders.

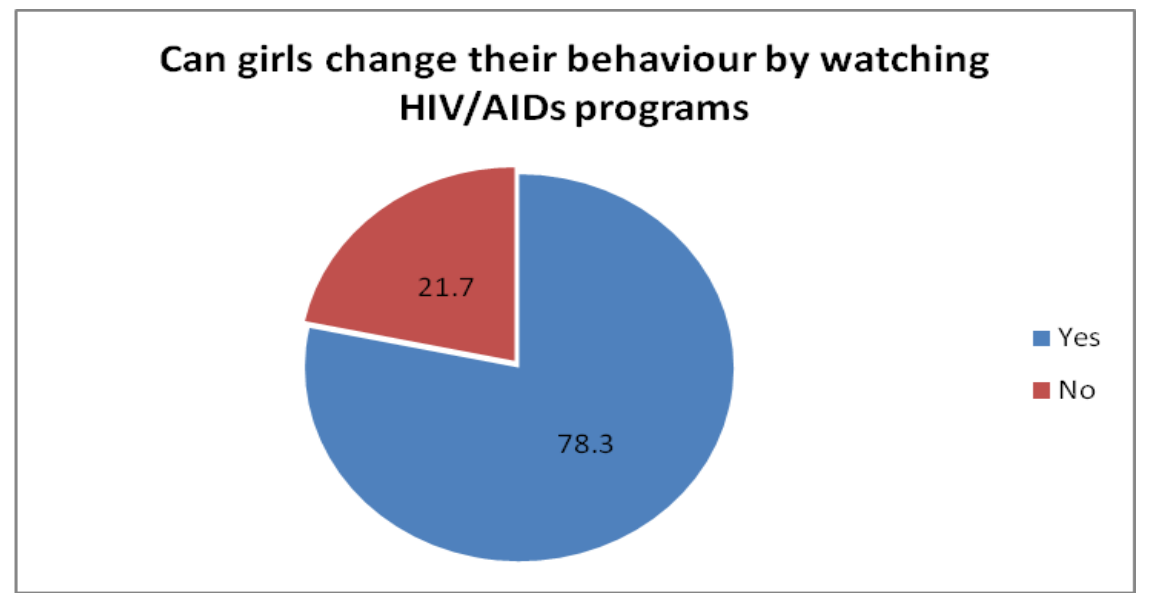

Figure 14: can girls change behavior by watching TV (\%)

On whether girls can change behavior by watching TV programs on HIV/AIDS alone $78.3 \%$ said yes while $21.7 \%$ said they cannot.

Table 1: what else can be done

\begin{tabular}{lll}
\hline \hline If no what else needed to change & Frequency & Percent \\
\hline A lot of open forums & 1 & 10 \\
Avoid being idle & 1 & 10 \\
Be very principled & 1 & 10 \\
Families need to talk to children & 1 & 10 \\
More counseling to be empowered to say no to sex & 4 & 40 \\
Not having sex before marriage & 1 & 10 \\
Watch other programs eg soccer so that they use their leisure time & 1 & 10 \\
wisely & 10 & 100 \\
\hline Total &
\end{tabular}

For those who felt that girls cannot change behavior by watching TV programs alone, they gave several suggestions on what else should be done to help them change behavior. Many of the respondents $40 \%$ said that there was need for more counseling to empower the girls to say no to unprotected sex. Others, (10\%) said that there should be open forums where girls can speak openly about circumstances that affect them and make them vulnerable to HIV/AIDS. Another $10 \%$ said that girls should avoid being idle because that leads them into temptation. Another $10 \%$ said that girls 
should be principled and say no to sexual advances from men who expose them to the risk of HIV infection; another $10 \%$ said that families or parents should talk to their children on issues of sex; yet another $10 \%$ said there should be no sex before marriage and another $10 \%$ said that girls should watch other programs like soccer so that they use their time wisely. The respondents felt that besides the TV messages; there was need for other activities to be included in the TV campaigns for positive behavior change to be achieved among the target population. For instance, $9.1 \%$ of the respondents felt that there is need to include experiences of people who are infected or affected by HIV/AIDs to make the messages more effective. They felt that when people get first hand information, it might have greater impact than just watching TV programs with messages on HIV/AIDS.

\section{Discussions of the results}

The findings of the study indicated that indeed Mlolongo Township is a high risk town due to the presence of truck drivers and recently sand harvesters. This situation, coupled with poverty levels make the female population in the town very vulnerable to HIV/AIDS. From the study findings, majority of the respondents either lived with relatives or with friends but there no women who lived on their own. This was an indication of high levels of poverty whereby people have to live together in order to cut down on living costs. The results also indicated that majority of the respondents $(76.7 \%)$ were not in any gainful employment, which made them turn to the truck drivers for financial support in exchange for sex. Many of the girls said that the male customers who demanded for unsafe sex paid them more money than those who had safe sex. This left the girls in a dilemma; whether to engage in unprotected sex and be paid more money but risk their lives to HIV/AIDS or engage in protected sex but get less money? The study also found out that all the respondents had access to TV; meaning that TV is an effective medium of communication that can be used in any campaign especially on HIV/AIDS. However, in spite of that, HIV infection was still on the increase among the women. Therefore whereas the study established that TV messages are relevant in addressing the HIV/AIDS among young women in Mlolongo Township, they did not result in positive behavior change.

\section{Conclusion}

From the findings, most respondents said that there was need for much more to be done up and above TV messaging to achieve behavior change. For instance, majority felt that there is need to include guidance and counseling in the prevention strategies, have more informative programs that are devoted specifically to HIV/AIDS while others felt that there was need to go back to the old strategies (inclusion of pictures of infected people) to serve as an example to those deliberately involved in risky behavior. There are those who felt that there is need to include infected or affected people in the campaigns because this may help drive the message home. So what this means is that TV viewership and personal behavior change cannot be achieved or there is no direct correlation between the two variables because majority of the respondents said that there was more that needs to be done up and above watching TV programs with messages on HIV/AIDS in order to achieve positive behavior change. Therefore HIV/AIDS prevention through messaging through TV is not the most effective strategy of addressing the vulnerability of young women to HIV and AIDS.

There was general agreement among the respondents that whereas the TV messages have served their purpose in creating awareness in the war against HIV/AIDS but they are not adequate by themselves to change behavior. There is more to be added if positive behavior change is to be achieved.

Based on the findings of this study the following conclusions are made: From the study findings, awareness of HIV/AIDS has been created at almost $100 \%$. This is because majority of the respondents had watched at least one TV program or another with a message on HIV/AIDS. This means that awareness creation has been achieved. However behavior change has not been achieved. The study concluded that TV messages alone cannot result in positive behavior change. There is also no relationship between TV viewership and personal behavior change and HIV/AIDS prevention messaging through TV is not the most effective methodology in addressing the vulnerability of girls to HIV/AIDS in Mlolongo Township.

\section{References}

[1] Afroline: The Voice of Africa:[online]< http//www.afroline.org:> Accessed on 13/05/2011

[2] A commonwealth Response to a Global Health Challenge. Commonwealth secretariat 2001

[3] Barnett T. and Whiteside. (2006). Aids in the Twenty-First Century Disease and Globalization. Palgrave Macmillan

[4] Barnett T. \& Whiteside A. (2002, 2006). AIDS in the Twenty First Century-Disease Globalization. Macmillan, New York

[5] Bulletin of World Health Organization 2004

[6] Chava Frankfort-Nachmias \&David Nachmis(1996). Research Methods in the Social Science $5^{\text {th }}$ Edition. St Martins Press London.

[7] Centers for Disease Control (CDC) HIV Prevention -United States MMWR 57 (39) October 2008.[online]< www.avert.org/USAStatistics.htm> Accessed on 12/06/2011

[8] Central Bureau of Statistics and Ministry of Health, Nairobi 2004

[9] C.R. Kothari (2007). Research Methodology, Methods \& Techniques $2^{\text {nd }}$ Edition, New Age Publishers, India

[10] Danya International. TB/HIV Communication Campaign. WHO. Africa Development Forum. [online]<org/Hiv News.htm> Accessed on 4/12/2010 
[11] Global Health Challenge on AIDS: A commonwealth Response to a Global Health Challenge. Commonwealth Secretariat, United Kingdom

[12] Deadline for Health: The media Response to Convey HIV/AIDS, TB and Malaria in Africa. International Women Foundation (Lisa Woll) September 2004

[13] International Journal of Gynecology and Obstetrics Vol. 100 Issue 12008 pg 45-51.

[14] Journal of Youth and Adolescence, Vol 24 No5 1995.

[15] Jane D. Brown. (1991). Television Viewing and Adolescent's Sexual Behavior. Journal of Homosexuality Vol. 21, Issue 1 \& 2.[online]http://www.information.com/smmpp/contet. Accessed 27/05/2011

[16] Kenya Demographic Health Survey 2007

[17] Kenya Demographic Health Survey 2008-2009

[18] Kenya Population and Housing Census 2009

[19] Kenya National Guidelines on Nutrition and HIV/AIDS MOH, January 2007

[20] Kenya national Guidelines for Research and Development on HIV/AIDS Vaccines 2005.

[21] Kenya National HIV/AIDS Strategic Plan 2005 -2010.

[22] Kenya Vision 2030: Machakos District development Plan 2008-2012.

[23] Mugenda M. O. \& Mugenda A.G. (2003). Research Methods: Quantitative and Qualitative. Acts Press, Nairobi, Kenya.

[24] McQuail D. (2005): Mass Communication Theory $5^{\text {th }}$ Edition, Southampton, UK

[25] Ngugi E. \& D. Jackos(1996). STD Control in Female Commercial Sex Workers in Africa. Univesity of Nairobi

[26] Ngugi E. (1999). Behavior Surveillance \& STD Seroprevalence Survey: Female sex workers: Strengthening STD/HIV/AIDS Control. University of Nairobi, Nairobi.

[27] Ndeti N. (2011). HIV/AIDS, Communication and Secondary Education. Nairobi, Kenya

[28] Nicholas W. (2005). Your Research Project. Sage Publications, London.

[29] Tasmin W (1997). Endangering AIDS, Deconstructing Sex, Text and Epidemic. Sage Publications, London.

[30] Tan A. S. ( 1985). Mass Communication Theory and Research, Second Edition,Texas Tech University, New York

[31] UNAIDS/WHO (2009): Uniting the World Against AIDS www.unaids.org

[32] UNAIDS 2004

[33] UNAIDS Technical Consultation on Social Communication (August 2007).

[34] WHO: Gender Inequalities and HIV:[online] <http//www.WHO.int/gender/hiv_aids>Accessed on 11/5/2010

[35] Women and HIV Basic Information Sheet: The Well project:[online]<http//www.thewellproject.org/en>Accessed on 17/05/2011

[36] Springerlink-Journal of Youth and Adolescence, Volume 25 No. 5 [online] $<$ http//www.springerlink.com/> . 27/05/2011

[37] Taranlola D. Lamtey P. (1997). The Status and Trends of the HIV/AIDS Epidemic in Sub-Saharan Africa-Provisional Report. Abidjan Cote D'Voire Dec. 1997.

[38] The Body.org. The Complete HIV Resource[online[<http//whois.domaintools.com/the body.org>Accessed on 5/11/2010

[39] Oriare P. Ugangu W. \& Okello. R (201). The Media we Want: Kenya Media Vulnerability Study.Friedrich Eibert. Stiftung, Nairobi.

[40] WHO (2006). Preventive HIV/AIDS in Young People; Evidence from Developing Countries. Who Technical report Series No. 938

[41] Wyss K Preventive Interventions to Control and Combat the Spread of HIV in Africa: A review on what Works and what does not. A Commission Paper Established in the Context of the Mandate. 751-14/VGU/SKM/REM of the Swiss Agency for Development and Corporation (SDC) 